\title{
Comunicación intercultural y cultura laboral en una maquiladora trasnacional en Yucatán: un enfoque interdisciplinario
}

\author{
Verónica Soledad Garza Navejas* \\ Gretty Guadalupe Escalante Góngora** \\ UNIVERSIDAD DEL MAYAB
}

El presente trabajo se inserta en las investigaciones sociales contemporáneas que analizan los cambios en materia laboral producidos por el proceso de globalización que vivimos hoy en día. Particularmente nos interesa explicar cómo la industria maquiladora trasnacional contribuye a la construcción de una nueva cultura e identidad laboral, en trabajadores y trabajadoras de origen maya y el papel que juega la comunicación intercultural en esas transformaciones. Presentamos los primeros resultados de un estudio interdisciplinario llevado a cabo en una maquiladora de capital estadounidense ubicada en una población rural de Yucatán, que tiene entre sus características emplear trabajadores de diferentes orígenes lingüístico-culturales (maya-yucatecos, mexicanos de otras regiones del país y estadounidenses). La metodología empleada fue la etnografía, es decir, la observación a los sujetos de estudio (obreros, obreras, mandos medios y gerenciales) en su espacio laboral, así como el uso de técnicas de investigación tales como entrevistas e historias de vida.

Palabras clave: Comunicación intercultural, industria trasnacional, identidad laboral.

\footnotetext{
* Licenciada en Antropología Social por la Escuela Nacional de Antropología e Historia, con maestría en Ciencias Antropológicas por la Universidad Autónoma de Yucatán y ProfesoraInvestigadora del Centro de Investigaciones en Ciencias de la Comunicación Anahuac-Mayab. Correo electrónico: garzanave@yahoo.com

** Licenciada en Ciencias de la Comunicación y Maestra en Educación por la Universidad del Mayab. Profesora- Investigadora del Centro de Investigaciones en Ciencias de la Comunicación Anahuac-Mayab. Correo electrónico: ggescala@unimayab.edu.mx
} 
This paper belongs to contemporary social research focused on the changes which result from present globalization processes, it specially attempts to offer an answer to the question how transnational industries contributes to the constitution of work culture and identity in individuals with Mayan cultural backgrounds, and what is the role that intercultural communication plays in. This is a work in progress, so we present the first results of an interdisciplinary study carried out an assembly plant, of American capital, located in a rural village of Yucatan which one of its main features is the presence of workers with different cultural and linguistic backgrounds (Mayan-yucateco, Mexican from other places than Yucatan, and American people). The used methodology was ethnographic in character, it means, observation of individuals at its working place, so well opened and addressed interviews and histories of life.

Key words: Intercultural communication, transnational industries, work identity.

\section{INTRODUCCIÓN ${ }^{1}$}

El proceso socioeconómico que conocemos como globalización, tiene entre sus características la producción industrial distribuida a lo largo y ancho del planeta. Las grandes corporaciones internacionales instalan sus fábricas por diversas regiones geográficas. Por ejemplo, la elaboración de una mercancía en México (pantalones de mezclilla o jeans) se realiza con capital, materias primas y tecnología de procedencia extranjera. Dicho proceso, nos dice Reygadas (2002), requiere del flujo internacional de: productos, empleados, información, planes de trabajo, etcétera., así como de símbolos de distinta naturaleza, marcas y logotipos, tanto de las empresas como de sus mercancías.

Así, las corporaciones emplean personal de distintas nacionalidades y los productos se comercializan en diferentes lugares del mundo. A esto debe sumarse que los métodos de organización del trabajo con frecuencia incorporan experiencias y técnicas procedentes de diversas latitudes; lo que ha dado origen a una industria de carácter mundial apoyada por una nueva clase de experticia en

\footnotetext{
${ }^{1}$ Este artículo se basa en la ponencia presentada en el xiv Encuentro del Consejo Nacional de Educación e Investigación en Ciencias de la Comunicación. Nuevas Perspectivas de la Comunicación, Actores, Escenarios, celebrado en Boca del Río, Veracruz, el 17 y 18 de octubre de 2007.
}

240 - Verónica Soledad Garza Navejas, Gretty Guadalupe Escalante Góngora 
relaciones laborales, consultores que desarrollan y ejecutan los mismos sistemas gerenciales en distintas zonas alrededor del mundo.

El desarrollo tecnológico en materia de comunicación ha favorecido a la industria global en cuanto al rápido traslado de materias primas, maquinaria, consultores y publicidad. Ejemplo de ello es que una maquiladora en Estados Unidos puede adquirir en una semana, maquinaria procedente de Japón, telas de México y botones de India. Asimismo, la televisión satelital e internet ayudan a que la publicidad llegue a todos los rincones del planeta traducida en diferentes lenguas. Igualmente, el fax y el teléfono celular facilitan la comunicación al interior de las empresas.

Otra de las características de la industria contemporánea es promover la cultura corporativa entre sus empleados. Ésta se puede explicar como una "nueva cultura laboral" creada por la empresa para que los trabajadores se identifiquen con los objetivos de la corporación, y colaboren en la búsqueda de mayor calidad productiva. Incluso, "en algunos casos se han puesto en marcha verdaderos programas de ingeniería cultural, orientados a adecuar los valores y las actitudes de los trabajadores a los nuevos requerimientos de la producción industrial" (Reygadas, 2002, p. 19). Sin embargo, a pesar de este fomento cultural por parte de las corporaciones, los trabajadores añaden a la "cultura corporativa” sus experiencias, habilidades y concepciones del trabajo; de ahí que en muchos casos, las culturas laborales de los empleados, como se explicará posteriormente, se construyen como resultado de la fusión de la cultura laboral de los trabajadores previa a la fábrica, con la promovida por las empresas.

Entendemos a la cultura laboral como "el proceso de creación, transmisión y apropiación de significados que tienen lugar en el mundo del trabajo" (Reygadas, 2002, p. 19). En otras palabras, pensamos que es en la vida laboral donde se crean y recrean una serie de símbolos y significados entre quienes comparten un oficio y un espacio de trabajo. Los trabajadores crean su cultura de trabajo al compartir conocimientos, lenguajes, problemas, padecimientos; así como las maneras de enfrentar estos últimos. Igualmente, en el espacio laboral se producen identidades, en la medida en que se promueve que los empleados que comparten un oficio se reconozcan como "nosotros" en relación y oposición a "los otros", aquellos que consideran diferentes.

Cabe mencionar que uno de los principales rasgos de la industria globalizada es la diversidad cultural al interior de sus fábricas, que son espacios en los que se presenta interacción entre empleados de diferentes orígenes lingüísticos y culturales. Con frecuencia, esta diversidad conduce a problemas en la comu-

Comunicación intercultural y cultura laboral en una maquiladora $\bullet 24 \mathrm{I}$ trasnacional en Yucatán: un enfoque interdisciplinario 
nicación que se establece como parte de las relaciones laborales entre empresa y empleados, debido a que muchas veces no comparten idioma y costumbres. Incluso, en ocasiones, la falta de entendimiento impide el buen desempeño de los objetivos de la empresa y la satisfacción de las necesidades y derechos de los trabajadores.

El objetivo de este escrito es explicar cómo se va construyendo una cultura e identidad laboral en una empresa maquiladora trasnacional inserta en una comunidad rural, y el rol que juega la comunicación en ese proceso; se pretende también comprender si se trata de un proceso impositivo de la empresa hacia los trabajadores, como parte de la "nueva cultura laboral o cultura corporativa" o más bien de un modo en que los trabajadores, junto con la empresa, van configurando su cultura e identidad laboral en la cotidianidad.

Para ello elegimos una planta maquiladora trasnacional estadounidense de gran importancia en la entidad, por la generación de empleos en los tres municipios en donde se localizan sus naves productivas y por la derrama económica que representa para dichos municipios y para el Estado. Esta empresa trasnacional produce pantalones y cuenta con tres plantas maquiladoras en dos zonas geográficas de Yucatán: dos de ellas en la zona henequenera al centro y norte del Estado, y una en la zona citrícola, al sur del mismo. Es preciso subrayar que omitimos el nombre de la empresa por solicitud de dicha organización, ya que por reglamento interno, no puede proporcionar información al exterior de la planta.

Para entender la identidad laboral abordaremos las relaciones interculturales, es decir, la manera como interactúan cotidianamente los trabajadores que integran la empresa pues poseen diferentes idiomas y orígenes culturales. Consideramos importante analizar los procesos de comunicación que se presentan entre dichos actores sociales, ya que nos permite entender cómo la empresa transmite la identidad laboral a sus empleados, así como la concepción que tienen del trabajo, y la idea compartida de "nosotros" ante los "otros". Es decir, de aquellos con quienes se relacionan y a los que consideran diferentes.

Las principales preguntas de las que partimos fueron: ¿cómo se expresan las relaciones interculturales en una empresa étnicamente diferenciada en donde los empleados gerenciales son estadounidenses, los mandos medios mexicanos y los obreros de origen maya-yucateco ${ }^{22}$ ¿cuáles son los procesos de cambio cultural en materia laboral que se presentan en los trabajadores al integrarse en

\footnotetext{
${ }^{2}$ Por población de origen maya entiéndase personas que nacieron en una familia mayahablante y que son partícipes de elementos culturales que caracterizan a esa etnia.
}

242 - Verónica Soledad Garza Navejas, Gretty Guadalupe Escalante Góngora 
una empresa trasnacional? ¿cuáles son las formas de comunicación presentes al interior de la empresa? ¿se está construyendo una identidad laboral en donde los empleados de la maquiladora se identifiquen con la empresa? ¿cuáles son las estrategias comunicacionales de la maquiladora para transmitir esa identidad laboral?, entre otras.

Esta investigación surge como una iniciativa del cicam (Centro de Investigación en Comunicación Anáhuac Mayab), el cual tiene entre sus líneas de investigación la Comunicación Corporativa, especialmente entender la cultura organizacional de la región geográfica en el que está inmerso. De hecho, este trabajo se realizó a través de un enfoque interdisciplinario entre la antropología y la comunicación, por la interesante combinación de los métodos de investigación propios de cada área de estudio.

En este sentido, se trabajó desde la perspectiva cualitativa, a través del método etnográfico; se realizó observación de los procesos productivos, procesos de comunicación y relaciones laborales que se establecen al interior de la empresa. El estudio se inició en noviembre de 2006 y culminó en septiembre de 2007, con dos períodos de trabajo de campo. El primero, en marzo y abril de 2007 y el segundo, en julio -agosto y septiembre del mismo ańo; éste consistió en realizar observación directa a los sujetos de estudio (obreros, mandos medios y gerenciales) tanto en la localidad donde habitan como al interior de la maquiladora. Además se realizaron entrevistas abiertas y dirigidas e historias de vida.

El trabajo está dividido en cuatro partes: en la primera presentamos algunos antecedentes de los estudios laborales realizados en México, con la idea de proporcionar información sobre las investigaciones en cuanto a cultura e identidad laboral se refiere; en la segunda ofrecemos un resumen de la situación histórica de las maquiladoras en Yucatán y de esa manera situar al lector en el contexto socioeconómico que viven los nuestros sujetos de estudio; en la tercera describiremos las características generales de la maquiladora en relación a la diversidad cultural y los sujetos de estudio. Finalmente, en la cuarta parte, analizaremos la comunicación intercultural al interior de la empresa, sobretodo durante el proceso productivo y de qué manera se va construyendo una cultura e identidad laboral entre los operarios y operarias.

\section{ESTUDIOS SOBRE CULTURA LABORAL EN MÉXICO}

Los estudios sobre el trabajo en México, básicamente los de antropología, se remontan a la década de los setentas y ochentas del siglo xx. Éstos se preocu-

\section{Comunicación intercultural y cultura laboral en una maquiladora $\bullet 243$ trasnacional en Yucatán: un enfoque interdisciplinario}


paron por explicar los procesos sociales que se presentaban en las fábricas y otros espacios laborales. A pesar de sus importantes aportaciones, sobre todo en lo correspondiente a la vida cotidiana, organización gremial y luchas obreras, presentaron limitaciones en los procesos relacionados con la cultura de los trabajadores. Se podría decir que las investigaciones pioneras fueron las de los mineros de Coahuila realizadas por Victoria Novelo, Augusto Urteaga y Juan Luis Sariego, quienes presentan por primera vez el concepto de cultura obrera (Reygadas, 1998). Dicho término fue cuestionado por Guillermo Bonfil Batalla y otros académicos, en un congreso nacional de antropólogos mexicanos (Nieto, 2005). Sin embargo, este concepto cambió al de cultura del trabajo, dada la imposibilidad de concebir homogéneamente a la clase obrera.

Durante la década de los noventas, se plantea una nueva propuesta para el estudio antropológico de los trabajadores en México, en donde se propone el concepto de cultura de trabajo e identidad laboral. A esto se suma la importancia de analizar los significados del trabajo existentes en distintos grupos de trabajadores y las diferencias internas en cuanto a edad, género y etnicidad. Nos referimos a las investigaciones realizadas por Nieto (1997), De la Garza (1997) y Reygadas (1998) por citar a algunos autores.

En el caso de Yucatán, los estudios sobre las maquiladoras han sido importantes desde la década de los 80 's, siendo Beatriz Castilla y Beatriz Torres investigadoras pioneras. Por ejemplo, en el trabajo Mujeres mayas en la robótica $y$ lideres de comunidad tejiendo la modernidad del 2004, Beatriz Castilla analiza la construcción de la identidad laboral de las obreras mayas trabajadoras de Ormex, primera maquiladora que se instala en el Estado y se dedica a ensamblar piezas dentales.

Por otro lado Luís Alfonso Ramírez (2004) ha reconstruido la historia de las maquiladoras trasnacionales en Yucatán y las relaciones que éstas han tenido tanto con el Gobierno del Estado como con empresarios locales. Ha analizado las políticas de empleo y atracción del capital extranjero. A pesar de la relevancia de estos trabajos, existen pocos análisis etnográficos que han abordado la observación en las fábricas en Yucatán, por lo que consideramos importante investigar sobre los cambios de vida de los trabajadores, la cultura del trabajo, la identidad laboral, la comunicación intercultural y cómo las maquiladoras han modificado la dinámica socioeconómica y cultural de las localidades en las que se instalan.

244 Verónica Soledad Garza Navejas, Gretty Guadalupe Escalante Góngora 
La crisis económica que ha vivido México durante las últimas décadas, ha orillado a que el Estado promueva la inversión extranjera, tanto en el terreno financiero, productivo y comercial. Al respecto, la industria maquiladora trasnacional ha jugado un papel importante en la generación de empleos y en la exportación de productos manufacturados. Esta industria se introdujo al país en el año de 1965 a través del Programa Industrial Fronterizo, cuyo propósito fue combatir el desempleo y reubicar a los trabajadores mexicanos que regresaban de Estados Unidos, una vez que concluyó el Programa de Braceros (1940-1965). Así, las primeras maquiladoras trasnacionales se ubicaron en los estados fronterizos, principalmente en las ciudades de Tijuana, B.C. y Ciudad Juárez, Chihuahua. Después de la industrialización fronteriza, la expansión de las maquiladoras trasnacionales se realizó hacia el centro y sureste mexicano, presentando un incremento a partir de la década de los noventa.

Con relación al caso de Yucatán, durante los setentas, el sector agrario sufre una crisis estructural, cuya causa principal fue la debacle henequenera, ya que la fibra de henequén fue el eje de la economía del Estado por más de un siglo. Pese a los intentos aislados de incentivar la producción agrícola nunca se logró recuperar el sector agropecuario y en los años ochentas se observa la caída drástica de la población económicamente activa del sector primario para ceder el paso al sector terciario. ${ }^{3}$ La reconfiguración del espacio regional (Tabasco con el petróleo y la emergencia de Cancún como polo turístico en los setentas) convirtieron a la ciudad de Mérida como la capital regional: sede del comercio y de los servicios. El sector terciario y el de la construcción demandaron una abundante mano de obra barata y móvil para atender el desarrollo de la infraestructura turística de las zonas del Caribe y de Tabasco. Tales eventos detonaron los flujos migratorios de trabajadores rurales a la ciudad de Mérida, a Cancún y a los Estados Unidos.

Con objeto de ofrecer fuentes de empleo el Estado emprende la transformación de la economía y sustituye el antiguo modelo de desarrollo agroexportador, basado en el monocultivo del henequén, y crea el Programa de Reordenación Henequenera y Desarrollo Integral de Yucatán en 1984. Con este programa el Estado prioriza la introducción de capital extranjero a la entidad, a través de la industria maquiladora trasnacional (Castilla y Torres, 1999, p.1).

${ }^{3}$ Ver Castilla Ramos, 1991. La ocupación en Yucatán.

Comunicación intercultural y cultura laboral en una maquiladora $\bullet 245$ trasnacional en Yucatán: un enfoque interdisciplinario 
Para atraer al capital extranjero, el Estado proporciona a los inversionistas libertad de aranceles, financiamientos e infraestructura: una amplia red de comunicaciones aérea, portuaria y carretera. Asimismo, se amplía el Aeropuerto Internacional y el muelle fiscal en Progreso, se fortalecen los servicios públicos en la Ciudad Industrial y se edifica el Parque de Industrias no Contaminantes en la carretera Mérida-Progreso. Cabe señalar que en la construcción de estos parques industriales, participó el empresariado yucateco, a través de la edificación de naves industriales para la instalación de plantas maquiladoras (Ramírez, 2004).

A partir de la década de los noventa, la industria maquiladora trasnacional en Yucatán, ha jugado un papel relevante en la economía del estado. Esto se ha reflejado principalmente en la derrama económica y en la generación de empleos; teniendo entre una de sus características la diversidad, en cuanto a ramas productivas. Entre las predominantes se encuentra la industria de la confección, seguida por la textil, joyería, equipo eléctrico y electrónico, aparatos dentales y procesadoras de alimentos (Castilla y Torres, 1999; Castilla y García, 2006). El predominio de la industria de la confección se explica porque Yucatán cuenta con mano de obra previamente capacitada en el ramo, acostumbrada a trabajar en la elaboración de telas y en confeccionar prendas. Esta habilidad se remonta a épocas muy antiguas, ya que desde la colonia, las mujeres mayas producían mantas de algodón en telar de cintura (patíes), como tributo para la corona española (Castilla y García 2006). ${ }^{4}$ Sin embargo, el interés gubernamental por promover la industria maquiladora de autopartes y la electrónica no ha obtenido buenos resultados, ya que la entidad no cuenta con mano de obra capacitada en estas áreas, a pesar de los esfuerzos que se han hecho en materia de educación técnica (Castilla y Torres, 1999; Ramírez, 2004, p. 92).

Una de las características de las maquiladoras en Yucatán es su capital norteamericano, europeo y asiático. En consecuencia, existe una diversidad étnica en el personal que contratan para ocupar ciertos puestos. Los empleados de origen extranjero son los que ocupan los puestos directivos; mientras que los nacionales, proceden de la ciudad de Mérida, del norte, centro y otros estados del sureste del país, los cuales se ubican en los mandos medios y gerenciales. Finalmente, la población maya-yucateca constituye el grueso de los trabajadores

\footnotetext{
${ }^{4}$ Desde el siglo XIX, las mujeres mayas han bordado su indumentaria tradicional (huipiles y ternos) para autoconsumo; intensificando la actividad en las últimas décadas, con objeto de abastecer al mercado turístico (Villanueva, 1993; Ramírez, 2004; Garza, 2005).
}

246 Verónica Soledad Garza Navejas, Gretty Guadalupe Escalante Góngora 
(obreros, supervisores y otros servicios), cuyos orígenes se encuentran en las áreas rurales del Estado.

\section{DiVERSIDAD CUltural EN LA MAQUiLADORA}

La empresa trasnacional que se investigó en este trabajo, como antes indicamos, está dedicada a la fabricación de pantalones. Sin embargo, en la planta observada, se realizan solamente el corte, acabados y terminados, principalmente pantalones de mezclilla (jeans) "corte vaquero", cuyas marcas son conocidas a nivel mundial y su consumo predomina en Texas, y los Estados del norte del país.

Esta planta se encuentra a 33 kilómetros de Mérida en dirección sureste, justo 400 metros de la carretera Mérida-Chetumal, en lo que se conoce como la ex-zona henequenera, en la cabecera municipal de uno de los 106 municipios de Yucatán; además, es la sede divisional ya que las oficinas y la gerencia general se encuentran en la misma planta. Se estableció en el ańo de 1997, en el marco de la política de diversificación productiva de la zona henequenera.

Aunque no contamos con un dato exacto sobre el número de empleados, por los datos obtenidos en las entrevistas, se calcula que la planta contrata aproximadamente a mil operarios o trabajadores directos; y cien trabajadores indirectos (empleados de limpieza, mecánicos, técnicos, ingenieros y administrativos). A continuación describiremos las características de la empresa, lo que observamos al interior de la maquiladora y el análisis que realizamos al interpretar el material empírico.

\section{a) Proceso productivo}

El proceso productivo de los pantalones a grandes rasgos es el siguiente: se recibe la materia prima (mezclilla y otras telas de algodón) que procede de Estados Unidos y del norte de México. Se corta la tela de acuerdo con moldes ya estandarizados y se pegan algunas partes chicas (bolsas) en la planta observada; después, se distribuyen estas piezas para ser armadas en las otras dos plantas ubicadas en diferentes municipios de Yucatán. Una vez armados, los pantalones regresan a la maquiladora en cuestión para el proceso de terminado (lavado, planchado, etiquetado, y empaque). Finalmente, el control de calidad se realiza también en esta planta y es la última parte del proceso antes de que el producto sea enviado a su destino comercial. De esta forma, las tres plantas maquiladoras juegan un papel importante en todo el proceso productivo de la fabricación de pantalones.

Comunicación intercultural y cultura laboral en una maquiladora 247 trasnacional en Yucatán: un enfoque interdisciplinario 


\section{b) Jornadas de trabajo}

Como muchas otras maquiladoras del país, en esta planta las máquinas no dejan de trabajar ninguno de los siete días de la semana; eso significa que hay operarios trabajando las 24 horas del día, prácticamente los 365 días del año. Para estos trabajadores el horario se divide en dos turnos de doce horas cada uno: de 6:00 a.m. a 6:00 p.m. y de 6:00 p.m. a 6:00 a.m. Hay cuatro turnos (a, b, cyd), de tal manera que trabajan cuatro días a la semana y cuatro descansan. En el caso de los administrativos y gerentes de planta, cubren un horario de corrido entre las 7:00 y 18:00 horas.

\section{c) Políticas de la empresa}

De la misma forma como la maquiladora observada trabaja con horarios y procesos de producción ya estandarizados y establecidos a nivel corporativo, así también opera con ciertas políticas básicas que forman parte de su esencia como empresa trasnacional. A continuación se describirá brevemente algunas de las más importantes con el fin de sentar los parámetros necesarios que ayuden en la comprensión de los resultados y análisis que se realizaron.

El corporativo tiene plantas maquiladoras en diferentes partes del mundo; su permanencia y crecimiento en este sentido se relaciona ampliamente con sus políticas de respeto e integración de la empresa con la comunidad en la que se inserta, como parte de la cultura corporativa o empresarial.

La empresa se relaciona directamente con la comunidad primero, a través de las contrataciones a personas de la misma localidad, principalmente como operarios con la intención de respetar la cultura de origen de los empleados, en este caso, las costumbres y tradiciones de los mismos. En segundo, a través de un día especialmente programado, la empresa brinda beneficio a población que la rodea (a la cual pertenecen muchos de sus empleados) a través de, por ejemplo, la construcción de parques, bibliotecas, pintar escuelas, etc. Esta actividad es interesante porque aunque es financiada económicamente por el corporativo, son los mismos trabajadores quienes la concretan con su mano de obra.

Otra de las acciones de la empresa que interpretamos como cultura corporativa y es de las más conocidas entre los empleados es la política de puertas abiertas. Ésta consiste en proporcionar a todos los trabajadores la posibilidad de acercarse a cualquier autoridad en caso de tener algún problema o querer hacer algún comentario, sin necesidad de limitarse a sus jefes inmediatos.

Con la política de no discriminación el corporativo promueve que todos los empleados, hombres y mujeres, tengan las mismas posibilidades y derechos 
en la empresa; si en algún momento alguien hace referencia a diferencias relacionas con su género o características físicas incluso, eso puede considerarse discriminación y ser reprendidos en caso de comprobarse.

Las política de seguridad consiste en cumplir altos estándares de calidad para alcanzar las certificaciones que como corporativo gozan; eso implica por supuesto el cuidado de la salud y seguridad de la planta para todos los trabajadores, especialmente de los que operan las máquinas. Las normas en este caso, van desde las más básicas como protectores para los ojos y oídos desde el momento de entrar a la planta, hasta las normas para encender y apagar las máquinas, rutas de evacuación más adecuadas para cada zona de trabajo e incluso normas de ergonomía para evitar la deformación de la columna o de los pies por las largas jornadas de trabajo.

\section{d) Sujetos de estudio}

Los operarios proceden de la localidad donde se ubica la maquiladora, y de otras poblaciones del mismo municipio. Nos referimos a mujeres y hombres entre dieciocho y cuarenta años. Son mujeres y hombres que tienen como antecedentes ser de origen maya-campesino. Eso significa que provienen de familias en donde la mayoría de padres y abuelos cultivaban la tierra (siembra de milpa y hortalizas en pequeñas parcelas). Los menos se dedicaban a otras ocupaciones: albañilería y jardinería, tanto en la ciudad de Mérida como en la Rivera Maya. Por su parte, el trabajo de madres y abuelas de las empleadas era en el hogar o como trabajadoras domésticas en la ciudad capital. Muchos de los operarios y operarias antes de entrar a trabajar a la maquiladora habían laborado en otras plantas de Mérida, yendo y viniendo de su localidad a esa ciudad todos los días. Los operarios más jóvenes, eran recién egresados de educación básica o media superior.

En cuanto a los otros integrantes de la planta, además de los operarios (que son la mayoría) están los gerentes y demás responsables de producción y los administrativos. El gerente divisional y los gerentes de las plantas son de origen estadounidense, excepto uno de ellos que es de Costa Rica; la gerencia de recursos humanos y mandos medios (administrativos, ingenieros de producción) son mexicanos de diferentes lugares: Yucatán, Distrito Federal, Monterrey, Torreón y Veracruz. Por su parte, los supervisores, empleados de limpieza, mecánicos y trabajadores directos, al igual que los operarios y ope-

rarias, son de origen maya-yucateco y habitan el municipio donde se ubica la empresa.

Comunicación intercultural y cultura laboral en una maquiladora $\bullet 249$ trasnacional en Yucatán: un enfoque interdisciplinario 
Las relaciones interculturales se manifiestan de manera cotidiana en las pláticas formales e informales entre los empleados al utilizar los idiomas predominantes: inglés y español. Esto se observa también en el proceso productivo, específicamente en la forma como los trabajadores van aprendiendo las técnicas del trabajo, en la adquisición de experiencia en cada una de las operaciones que ejecutan, en los códigos de producción, en las instrucciones que reciben, en la música en español que escuchan durante la jornada laboral (cumbia, banda, baladas).

En relación a las manifestaciones culturales, éstas se observan desde la alimentación diaria al interior de la fábrica, en donde a solicitud de los empleados se cocina comida yucateca: cochinita pibil, fríjol con puerco, pavo en escabeche, panuchos, etcétera; el respeto por las tradiciones como la celebración del Hanal Pixan (día de muertos), el 12 de diciembre Día de la Virgen de Guadalupe y la Navidad considerados días inhábiles por la empresa por ser las festividades religiosas más importantes para los operarios. También se festejan otras tradiciones arraigadas en la localidad como el Día del Padre, Día de la Madre y el Día del Niño. Además la maquiladora ofrece un festejo especial de acuerdo a las costumbres del municipio.

ANÁLISIS DE FORMAS DE COMUNICACIÓN, CULTURA E IDENTIDAD LABORAL

De acuerdo con Miquel Rodrigo (1999, p.12), la comunicación intercultural se entiende como aquella que se da "entre aquellas personas que poseen unos referentes culturales tan distintos que se autoperciben como pertenecientes a culturas diferentes". Este autor explica que es durante la comunicación intercultural como se manifiestan las identidades sociales de los grupos en interacción produciéndose un fenómeno de atribución identitaria. De modo que, indagar sobre la comunicación intercultural es relevante, no sólo para entender el funcionamiento de la empresa, sino las relaciones que se establecen entre las personas que trabajan en su interior.

Este estudio se enfocó en detectar la comunicación intercultural que se establece al interior de la maquiladora; nos interesaba saber si se presentaba un choque cultural o problemas entre los empleados por no entender las normas o los conceptos del trabajo manejados en la empresa, sobre todo entre la población de origen maya. De hecho, pensamos que íbamos a encontrar mayahablantes al interior de la maquiladora, pero no fue así, ya que la empresa contrata trabajadores que hablen español y sepan leer y escribir en este idioma. Además de

250 Verónica Soledad Garza Navejas, Gretty Guadalupe Escalante Góngora 
que en la localidad donde se ubica esta planta maquiladora el uso de la lengua maya se ha reducido notablemente entre sus habitantes. ${ }^{5}$

Se encontraron presentes dos grandes formas de comunicación: verbal y no verbal. En la no verbal consideramos la comunicación impresa (avisos, carteles, uniformes y cheques de pago, entre otros), la comida, y la música de fondo que se escucha durante las jordanas de trabajo. Como se puede suponer, de esta forma es como prácticamente la empresa establece una comunicación permanente con los operarios. Un ejemplo claro de ésta, son los carteles de "no a la discriminación”, (no puede haber rechazo por raza, género o discapacidad) y "no al acoso sexual", (cualquier molestia de uno de los empleados a una mujer puede ser denunciado y se recurre a la sanción y al despido definitivo) los cuales además de que decoran las paredes de la planta maquiladora, les recuerdan a los operarios que la empresa está abierta a atender sus necesidades.

Respecto a la comunicación verbal, se presenta de diferentes formas, de acuerdo con los procesos de trabajo involucrados. Aunque el idioma oficial es español, en la comunicación a nivel gerencial se utiliza en gran medida el idioma inglés, entre empleados mexicanos que tienen relación directa con los gerentes estadounidenses y con otros empleados de la corporación a nivel internacional. Además de que la mayor parte de los manuales vienen escritos en ese idioma.

La comunicación verbal llevada a cabo entre los empleados mexicanos, en general es en español; aquí están incluidos los mandos medios y trabajadores directos (operarios). Este tipo de comunicación también se puede dividir en formal e informal. En la comunicación verbal formal están: el curso de capacitación e inducción que reciben los empleados de nuevo ingreso (explicación de formas de pago, políticas, metas de la organización, etcétera) el mismo proceso productivo y las juntas trimestrales que la gerencia organiza para informar a los empleados los objetivos alcanzados por la organización, las metas de productividad que se deberán cumplir y los avisos de interés general en relación a prestaciones, festividades, entre otros. Estas reuniones son dirigidas por los gerentes estadounidenses (en idioma inglés) hacia los operarios con la ayuda de un traductor. Según la gerente de recursos humanos, utilizar a un traductor en esas juntas para desarrollar la comunicación inglés-español, es un esfuerzo de la empresa por lograr una comunicación formal de tipo horizontal

${ }^{5}$ Se debe a dos factores fundamentales: 1) la relación cotidiana de los habitantes del municipio con la ciudad de Mérida por razones laborales, de estudio y servicio; 2) el incremento de la enseñanza del español en las escuelas públicas del municipio desde la década de los 70's.

\section{Comunicación intercultural y cultura laboral en una maquiladora $\bullet 25 \mathrm{I}$ trasnacional en Yucatán: un enfoque interdisciplinario}


entre gerencia y operarios, buscando con ello la opinión y participación de todos los empleados. Al respecto los operarios respondieron positivamente sobre esta acción de la empresa, ya que eran de los espacios donde podían expresar lo que opinaban y sugerir algunas mejoras, tanto en la producción como laborales.

Lo anterior nos hace recordar lo que afirma Esteban Krotz (2004), en su trabajo sobre los diálogos interculturales en la Península de Yucatán, en el que define al diálogo intercultural como aquel que se da sobre bases estructurales y actitudinales de igualdad. Si bien por un lado las reuniones trimestrales y la política de puertas abiertas demuestran el interés de la empresa por comunicarse y responder las necesidades de sus "asociados", habría que preguntarnos entonces por qué en los cursos de inducción las imágenes y el idioma de los videos son muy viejos y todavía traducidos burdamente del inglés al español. Es decir, no ha habido un video y una capacitación que responda directamente a las características de los empleados de origen maya.

Por su parte, la comunicación verbal utilizada en el proceso productivo tiene características particulares. Los operarios de origen maya que hablan espańol, aprenden el proceso de trabajo utilizando muchos vocablos en inglés con cierta familiaridad. Ejemplos concretos: el nombre de la mayoría de las máquinas y operaciones del proceso productivo como "hand sam" que es el raspado de los pantalones para deslavarlos y "San Blas", para referirse a otras de las operaciones, no tanto por la dificultad para pronunciar en otro idioma, sino porque lo adaptan a sus referentes culturales. En otros casos, los vocablos en inglés se han ido hispanizando. Según los ingenieros de producción, el no traducir todos los nombres se debe a que hay vocablos difíciles de convertir al español y en ocasiones son más cortos en inglés, facilitando la productividad.

En cambio, hay una serie de palabras que se han traducido al español; por ejemplo, las tarjetas en donde se anotan los imperfectos de las prendas, originalmente eran en inglés y posteriormente la empresa las escribió en español para ser entendidas por los empleados. De esta forma, dicho reiteradamente, el lenguaje del proceso productivo se conforma por vocablos en inglés e incluso su uso latinizado; de ahí que sea una combinación de ambas lenguas y por lo tanto de ambas culturas.

Un ejemplo de esta combinación de palabras la podemos observar en el fragmento extraído de una plática con un operario del área de lavado quien afirmó lo siguiente: 
"Todas las cosas que vienen [se refiere a las materias primas], vienen en inglés, no viene nada en español. Manejamos mayormente las promociones: sizes, pe-ces, pero cuando hay un cambio te lo explican en español y toda la cosa. A veces llegan mails directamente de Estados Unidos o mails directamente de la gerencia, sobre lavado, y lo traen, y te dicen: verifica que los códigos estén bien; si hay diferencias, te hacen referencia a otro código de lavado. Un código de lavado tiene una fórmula, para un tipo de pantalón, un estilo de pantalón, como por ejemplo éste [señala el pantalón que traía puesto], no lleva mucho químico. Para un pantalón con desgaste le llaman un San Blas, vienen unos códigos de unos pantaloncitos que llevan tinte...."

En cuanto a la comunicación verbal informal, están las conversaciones que se dan entre los operarios, entre estos y los mandos medios durante sus descansos y tiempos de comida o aún más, en actividades fuera del trabajo. Aunque como antes se mencionó, ningún empleado reconoció que hablaba la lengua maya, es en los momentos de esparcimiento (festividades y encuentros deportivos organizados por la empresa) donde más se observan las relaciones interculturales, pues cada uno expresa libremente su forma de hablar, sus hábitos alimenticios y sus aficiones.

En general, la comunicación intercultural que observamos al interior de la maquiladora, la podemos analizar como una forma de intercambio de mensajes producidos entre personas de diferentes idiomas y culturas. Esta comunicación se basa en un objetivo común: la productividad. El hecho de que los operarios tengan el interés de conocer las palabras utilizadas aún en un idioma que no sea el propio, lleva a que fluya la comunicación.

Respecto a la identidad laboral, entre las preguntas de las cuales partimos para el desarrollo de la investigación se encuentran las siguientes: ¿qué pasa con la identidad de los empleados, sobre todo de los operarios de origen maya, al integrarse a la planta maquiladora?, ¿se está construyendo una identidad laboral en donde realmente los empleados sientan orgullo de pertenencia a la fábrica?, ¿qué papel juega la empresa en esa identidad y cuáles son los canales de comunicación que utiliza para transmitirla?

De acuerdo a nuestro trabajo de campo en la maquiladora y las entrevistas e historias de vida, pudimos observar que la identidad corporativa está muy presente entre los empleados, no sólo en los operarios, sino en los trabajadores en general. En parte esto se debe a que las iniciales del corporativo (se representa con dos siglas de la empresa que son: FV que corresponden al nombre de la corporación a nivel mundial y el emblema de la empresa.) aparecen impresas en

Comunicación intercultural y cultura laboral en una maquiladora $\bullet 253$ trasnacional en Yucatán: un enfoque interdisciplinario 
la papelería, en los carteles de las políticas hacia los empleados, en uniformes, camisetas, gorras, etcétera.

Entendemos como identidad corporativa al:

...sistema de signos visuales que tienen por objeto distinguir -facilitar el reconocimiento y la recordación- a una empresa u organización de las demás. Su misión es, pues, diferenciar (base de la noción de identidad), asociar ciertos signos con determinada organización y significar, es decir, transmitir elementos de sentido, connotaciones positivas; en otras palabras, aumentar la notoriedad de la empresa (Costa, J., 2003, p.15).

En el caso de la maquiladora estudiada, las formas de transmisión de la identidad corporativa son implícitas, con excepción de los cursos de capacitación y los videos de inducción en donde todos los empleados conocen la identidad de la empresa y su misión. La identidad corporativa se transmite a través del lenguaje silencioso que representa tanto la simbología del emblema omnipresente en la maquiladora, como el orgullo que transmiten los gerentes por laborar en una empresa exitosa a nivel mundial.

Así, agregaremos que los empleados de la maquiladora, si bien se sienten orgullosos de pertenecer a una empresa como la estudiada, porque consideran que es la que mejor paga y en su comunidad goza de prestigio social; tienen una serie de preocupaciones como el estar conscientes de que la maquiladora en cualquier momento se puede ir de Yucatán, que el trabajo de doce horas diarias durante cuatro días junto con el trabajo nocturno los lleva a un desgaste físico que no les permitirá laborar a ese ritmo por muchos años, entre otras cosas.

Sin embargo, pensamos que la identidad laboral va mucho más allá de que los empleados identifiquen el emblema de la empresa y se sientan orgullosos de ella. Consideramos que la identidad laboral en realidad se construye al interior de la maquiladora en el momento que los operarios comparten un espacio, conocimientos, destrezas laborales y un mismo origen lingüístico-cultural; así como por reconocerse como "nosotros" en relación y contraposición a los "otros" (mandos medios y gerenciales) que consideran diferentes.

La observación realizada nos permite sugerir que existe una forma de imposición de elementos culturales ajenos a la cultura de los operarios (cultura impuesta) como el idioma inglés, la vestimenta, los estándares de calidad, la identidad corporativa; ello como parte de las prácticas al interior de una empresa trasnacional de capital estadounidense. Sin embargo, percibimos también, que

254 Verónica Soledad Garza Navejas, Gretty Guadalupe Escalante Góngora 
los operarios y operarias van adoptando esos elementos culturales e integrándolos en su vida cotidiana laboral de manera particular (lenguaje, conocimientos sobre el proceso de producción, formas de convivencia, normas de seguridad).

Esos procesos (de imposición en el primer caso, de apropiación en el segundo), pueden verse a la luz de la teoría de control cultural desarrollada por Bonfil Batalla (1987), para quien la cultura de un grupo social que ha pasado por procesos de dominación colonial -como es la población maya- está conformada por cuatro ámbitos culturales: a) la cultura autónoma característica del grupo en cuestión, originaria y que el grupo ha mantenido a lo largo del tiempo; b) la cultura apropiada, es decir, la que el grupo adquiere de otros grupos sociales en contacto; c) la cultura impuesta, entendida como aquellos elementos culturales que el grupo hegemónico obliga al grupo dominado a adquirir; y d) la cultura enajenada, que se presenta cuando el grupo dominante adquiere elementos de la cultura dominada y los utiliza para sus intereses. Según este autor, todo grupo social posee la capacidad de tener el control de su propia cultura, o sea, de mantener aquellos elementos de su cultura que son considerados importantes para conservar al grupo unificado, al mismo tiempo que adopta aspectos de otras culturas. Sin embargo, el control de la cultura de un grupo también puede verse amenazado por los sectores dominantes quienes imponen sus formas de ver y vivir el mundo.

Efectivamente, en el caso observado, se advirtió que la cultura laboral estadounidense se impone en la vida laboral de los trabajadores de origen maya, lo que nos permite plantearnos varias preguntas. Si en la maquiladora predomina la cultura del grupo hegemónico: ¿qué significan las diferentes acciones que la empresa realiza para el bienestar de sus asociados?, ¿para qué sirve el acercamiento con la localidad?, ¿es posible hablar de grandes problemas de comunicación entre personas de diferentes lenguas y culturas observadas en la fábrica cuando hay estándares tan bien definidos? Es decir, dónde queda el "choque cultural", al menos en la construcción del lenguaje laboral cuando los empleados entrevistados manifestaron no haber tenido dificultades en cuanto aprender los vocablos en inglés para desarrollar el proceso productivo, pues dichos vocablos los fueron incorporando conforme conocían el proceso de trabajo. De hecho, en muchas ocasiones, la manera de pronunciar los vocablos difiere de sus pronunciamientos en inglés, pero eso no representaba un problema para los trabajadores entrevistados, ni para la empresa, mientras se alcanzaran los objetivos de productividad y fluyera la comunicación. ¿Es esto un ejemplo de apropiación o de adaptación a la cultura laboral?, ¿`se puede hablar

\section{Comunicación intercultural y cultura laboral en una maquiladora $\bullet 255$ trasnacional en Yucatán: un enfoque interdisciplinario}


de resistencia cultural al hispanizar los vocablos en inglés que se incorporan al lenguaje en el proceso productivo?

Para nosotros, la adaptación de los trabajadores a las necesidades de la empresa y el que ésta integre a su vida laboral elementos culturales propios de operarios y operarias responde al cumplimiento de un objetivo fundamental: alcanzar las metas en productividad impuestas por la corporación, pues como nos dijo una gerente de recursos humanos: "el objetivo de la empresa es que se cumplan las metas de producción, y por eso vamos a estar bien con nuestros asociados [operarios y operarias], gracias a ellos comemos, y entre mejor estén, es mejor para todos nosotros".

\section{Conclusiones}

Como parte de los resultados preliminares de este estudio hemos concluido que el proceso de globalización a través de la industria maquiladora estadounidense localizada en una población rural maya de Yucatán está contribuyendo a los cambios en la cultura e identidad laboral de la población maya yucateca.

La cultura laboral que se está configurando entre los operarios y operarias de la empresa se debe a dos factores: por un lado, a la imposición de elementos culturales de la corporación trasnacional que promueve una nueva cultura laboral, al mismo tiempo que respeta elementos culturales de origen de las operarias y operarios. Por otro lado, son estos trabajadores quienes van adaptándose a este tipo de vida laboral, al mismo tiempo que contribuyen con elementos culturales propios: comida regional, música en español escuchada durante el proceso productivo, participación en los festejos organizados por la empresa de acuerdo a sus tradiciones locales (Día de Muertos, Día de la Madre, Día del Padre, Navidad) e imprimiéndole a su lenguaje laboral utilizado en el proceso productivo la latinización de vocablos en inglés que mencionamos anteriormente.

En cuanto a la comunicación intercultural observada en la empresa, se presenta de manera verbal y no verbal, a través del intercambio de mensajes entre grupos socioculturales distintos lográndose efectivamente un diálogo; pero este diálogo es desigual y si, como señala Krotz (2004) el diálogo intercultural requiere de condiciones de igualdad entre los grupos sociales que interactúan ¿realmente puede establecerse un diálogo igualitario entre una empresa globalizada que se localiza en una población rural que impone una serie de lineamientos a seguir para la productividad, y los trabajadores de origen maya 
que históricamente han vivido la discriminación por los no mayas?, ¿cuáles son las características efectivas de la comunicación que se da en una planta como la observada?

Pensamos que para lograr un verdadero diálogo intercultural en términos de igualdad, es importante que el Estado antes de echar a andar políticas de desarrollo dirigida a la población rural de origen maya, como es el caso del Programa de Reordenación Henequenera y Desarrollo Integral de Yucatán, en donde se introduce la industria maquiladora trasnacional, tome en consideración la opinión, sugerencias y características culturales de los conglomerados sociales a quienes van dirigidas. Asimismo, consideramos que debe comprometerse con el fomento al respeto hacia la cultura de origen de los trabajadores mayas e incidir en las empresas para capacitar a sus empleados en su lengua materna.

No queda más que seguir investigando sobre los procesos observados: ¿qué tanto el aprendizaje de un nuevo proceso de trabajo en donde se incorporan una serie de vocablos en inglés puede llegar a presenta problemas de comunicación?, ¿cómo se puede mejorar la comunicación en la organización sobretodo integrando elementos lingüísticos y culturales locales, principalmente en los carteles impresos y en los videos de capacitación?, ¿la cultura laboral que se está formando en la maquiladora se transmite al resto de la familia en los hogares de los trabajadores? Estas y otras preguntas surgen de la necesidad de continuar estudiando sobre los procesos de producción, apropiación y reconfiguración cultural que lleva una maquiladora transnacional en una población rural del Estado de Yucatán.

\section{REFERENCIAS}

Bonfil, G. (1987). La teoría del control cultural en el estudio de procesos étnicos. México: Papeles de la Casa Chata, año 2, núm. 3, CiesAs-SEP 23-43.

Castilla, B. (1991). La ocupación en Yucatán. Mérida: UADY.

Castilla, B. (2004). Mujeres mayas en la robótica y lideres de comunidad tejiendo la modernidad. Mérida: UADY.

Castilla \& García, (2006). "La industria maquiladora de exportación en Yucatán, 1984-2005”. En: F. X. Paunero (ed.) América Latina: Documentos territoriales. Girona: Documenta Universitaria (U. d G. Publicacions).

Castilla, B. \& Torres, B. (1999). Yucatán: la otra frontera o la desaparición del sistema agroexportador. En Certeza Económica, No. 13, Año III, ago-sep. 1999.

Costa, J. (2003). Identidad Corporativa. México: Trillas-Sigma.

De la Garza, E. (1997). Los estudios sobre la cultura en México: enfoques, balances y perspectivas. México: CONACULTA

Comunicación intercultural y cultura laboral en una maquiladora $\bullet 257$ trasnacional en Yucatán: un enfoque interdisciplinario 
Garza, V. (2005). Identidad laboral y artesanias: el caso de las bordadoras de Kimbilá Yucatán. Tesis de maestría no publicada, FCA-UADy, Mérida, Yucatán.

Gaultier, S. (2006). "Mundialización, espacios de maquila y movilidad maya en Yucatán”. En: L. A. Ramírez (coord.). Un secreto bien guardado. Mundialización y reestructuración productiva en Yucatán. México: UAM-Plaza y Valdés.

Krotz, E. (2004). Diálogos interculturales en la Península de Yucatán: perspectivas para las relaciones entre la sociedad maya y la no maya. Temas Antropológicos, 26, (1-2), 33-54.

Nieto, R. (2005). "La ciudad industrial y la cultura urbana”. En N. García Canclini (coord.). La antropología urbana en México. México: CONACUlTA-UAM- FCE.

Nieto, R. (1997). Ciudad, Cultura y Clase Obrera: una aproximación antropológica. México: Culturas Populares de México-conaculta-Casa Abierta al Tiempo.

Ramírez, L. (2004). Las redes del poder: corrupción, maquiladoras y desarrollo regional de México. El caso de Yucatán. México: Cámara de Diputados-uady-Porrúa.

Reygadas, L. (2000). Ensamblando Culturas: Diversidad y conflicto en la globalización de la industria. Espańa: Gedisa.

Reygadas, L. (1998). Mercado y sociedad civil en la fábrica: culturas del trabajo en maquiladoras de México y Guatemala, Tesis doctoral publicada, UAM-Iztapalapa, México.

Rodrigo, M. (1999). Comunicación intercultural. España: Anthropos.

Villanueva, N. (1993). Artesanias y economía campesina en Halachó Yucatán. Folleto de investigación núm. 4, Mérida: UADY

258 - Verónica Soledad Garza Navejas, Gretty Guadalupe Escalante Góngora 